\title{
No effect of vitamin D supplementation on cardiovascular risk factors in subjects with metabolic syndrome: a pilot randomised study
}

Stefania E. Makariou ${ }^{1,2}$, Moses Elisaf ${ }^{1}$, Anna Challa², Nikolaos Tentolouris ${ }^{3}$, Evangelos N. Liberopoulos ${ }^{1,3}$

\begin{abstract}
${ }^{1}$ Department of Internal Medicine, Medical School, University of Ioannina, Ioannina, Greece

${ }^{2}$ Child Health Department, Medical School, University of Ioannina, Ioannina, Greece ${ }^{3}$ First Department of Propaedeutic and Internal Medicine, Laiko General Hospital, Athens University Medical School, Athens, Greece
\end{abstract}

Submitted: 29 July 2017

Accepted: 31 July 2017

Arch Med Sci Atheroscler Dis 2017; 2: e52-e60

DOI: https://doi.org/10.5114/amsad.2017.70504

Copyright (c) 2017 Termedia \& Banach

\begin{abstract}
Introduction: Patients with metabolic syndrome (MetS) may have lower 25-hydroxyvitamin D (25(OH)VitD) serum levels compared with non-MetS individuals. Vitamin D (VitD) deficiency is associated with various cardiovascular disease (CVD) risk factors. Yet, the effect of VitD supplementation on MetS remains uncertain. Our aim was to examine the effect of VitD supplementation on CVD risk factors in MetS subjects.

Material and methods: This pilot study had a PROBE (prospective, randomised, open-label, blinded end-point) design. Fifty patients with MetS were included and randomised either to dietary instructions $(n=25)$ (control group) or dietary instructions plus VitD $2000 \mathrm{IU} /$ day $(n=25)$ (VitD group) for 3 months. This study is registered in ClinicalTrials.gov (NCT01237769).

Results: In both groups a similar small weight reduction was achieved. In the VitD group serum $25(\mathrm{OH})$ VitD levels significantly increased by $91 \%$ (from $16.0(3.0-35.0)$ to $30.6(8.4-67.0) \mathrm{ng} / \mathrm{ml}, p<0.001)$, while in the control group no significant change was observed (from $10.0(4.0-39.6)$ to 13.0 (3.5-37.0) $\mathrm{ng} / \mathrm{ml}$ ). In both groups triglycerides, high-density lipoprotein cholesterol, low-density lipoprotein cholesterol, fasting glucose, haemoglobin $\mathrm{A}_{1 \mathrm{c}}$, homeostasis model assessment index and diastolic blood pressure did not significantly change. Systolic blood pressure decreased by $3.7 \%$ (from $134 \pm 14$ to $129 \pm 13 \mathrm{~mm} \mathrm{Hg}, p=0.05$ ) in the VitD group, while it decreased by $1.5 \%$ (from $132 \pm 13$ to $130 \pm 16 \mathrm{~mm} \mathrm{Hg}, p=\mathrm{NS}$ ) in the control group ( $p=$ NS between groups). In the VitD group serum 25(OH)VitD increase was negatively correlated with SBP decrease $(r=-0.398, p=0.049)$.

Conclusions: VitD supplementation (2000 IU/day) did not affect various CVD risk factors in patients with MetS.
\end{abstract}

Key words: vitamin D, metabolic syndrome, hypertension, cholesterol, triglycerides, glucose.

\section{Introduction}

During the last few years vitamin D (VitD) has attracted the interest of the scientific community since apart from its central role in bone homeostasis, recent studies suggest its implication in various cell func-

\author{
Corresponding author: \\ Dr Evangelos N. Liberopoulos \\ MD, FASA, FRSH \\ Department \\ of Internal Medicine \\ Medical School \\ University of loannina \\ 45110 loannina, Greece \\ Phone: +302651007502 \\ Fax: +302651007016 \\ E-mail: vaglimp@yahoo.com, \\ makarioustefania@yahoo.com
}


tions. Indeed, VitD receptors (VDRs) may control about $0.5-5.0 \%$ of the total human genome, i.e. 100-1250 genes [1].

VitD deficiency (defined as serum 25(OH)VitD $<20 \mathrm{ng} / \mathrm{ml}$, according to the Institute of Medicine (IOM) estimations [2]), has emerged as a new "pandemic", as it may affect up to $50 \%$ of young adults and healthy children, accounting overall for up to one billion people worldwide, even in sunny areas. We also considered our patients as VitD deficient when having serum $25(\mathrm{OH}) \mathrm{VitD}<20 \mathrm{ng} / \mathrm{ml}$, although the "cut-point" value is a matter of discussion and some researchers regard it a common misconception [3]. This deficiency can be attributed to the modern sedentary lifestyle with reduced sun exposure [4], while obesity may be associated with one third of VitD deficient cases [5].

Interestingly, VitD deficiency has been associated with a wide range of diseases, such as cardiovascular disease (CVD), diabetes and malignancies as well as infective, autoimmune, and neurodegenerative diseases and even with overall mortality $[6,7]$.

In particular, metabolic syndrome (MetS) is often accompanied by VitD deficiency and low levels of serum $25(\mathrm{OH})$ VitD have been associated with metabolic disturbances in this setting [8-11], though not consistently [12-15]. Moreover, research regarding the effect of VitD supplementation on CVD risk factors in MetS subjects has not reached definite conclusions.

In this context we performed a pilot study testing the effect of VitD supplementation on various CVD risk factors (weight, body-mass index (BMI), waist circumference, systolic and diastolic blood pressure (BP)) and biochemical parameters (glucose homeostasis, lipids) in persons with MetS. This study is registered in ClinicalTrials.gov (NCT01237769).

\section{Material and methods}

\section{Study population}

This study had a PROBE (prospective, randomised, open-label, blinded end-point) design. All participants gave written informed consent before any clinical or laboratory evaluation and any dietary or drug therapeutic intervention. The study protocol was approved by the ethics committee of our institution and was conducted following the guidelines outlined in the Declaration of Helsinki.

Consecutive subjects with MetS were included. These subjects were diagnosed by fulfilling 3 or more of the National Cholesterol Education Program Adult Treatment Panel III (NCEP-ATP III) [16] criteria, when they visited the Outpatient Metabolic and Obesity Clinic of the University Hospital of Ioannina, Ioannina, Greece. Patients with dia- betes, chronic kidney or liver disease, triglycerides $>500 \mathrm{mg} / \mathrm{dl}(5.65 \mathrm{mmol} / \mathrm{l})$ and intake of calcium and/or VitD supplements as well as lipid-lowering medications were excluded from the study. Patients with elevated blood pressure (BP) who did not receive treatment participated in the study, as well as patients with hypertension who received stable treatment for at least 3 months and whose $\mathrm{BP}$ levels normalised during the intervention.

Eligible patients were randomly allocated (through a computer-generated sequence of random numbers) by sex and age as baseline factors to either only dietary instructions $(n=25$, Non-Suppl group) or to receive 2000 IU VitD/day (Vitamin $\mathrm{D}_{3}$, Lamberts) along with dietary instructions ( $n=25$, VitD Suppl group) for 3 months. We administered 2000 IU VitD/day, a higher than usual dose but within safety limits, since former studies failed to find any significant changes in CVD risk factors when using usual VitD doses (400800 IU/day). Supplementation of up to 2000 IU VitD daily has been deemed by the U.S. Food and Drug Administration's nutritional guidelines as more effective and safe [17]. Similarly, Endocrine Society clinical practice guidelines conclude that to raise serum $25(\mathrm{OH})$ VitD levels above $30 \mathrm{ng} / \mathrm{ml}$, intakes of 1500 to 2000 IU/day may be required [18]. All patients $(n=50)$ followed a 12-week dietary intervention programme according to NCEP ATP III guidelines [16]. The compliance with dietary instructions was assessed by completing food diaries and through discussion during follow-up visits, while compliance with study medication was assessed by tablet count at week 12 ; patients were considered compliant if they took $80-100 \%$ of the prescribed tablets.

In order to minimise the effect of sunlight on $25(\mathrm{OH})$ VitD levels, all specimens were collected during March to September, a season during which the duration of sunlight is approximately similar in Greece. Blood pressure was measured 3 times in the right arm of patients after a 10-min rest in a sitting position using an electronic sphygmomanometer (WatchBP Office, Microlife WatchBP AG, Widnau, Switzerland) and calculated as the average of the second and third measurement.

\section{Laboratory measurements}

All laboratory assays were performed after an overnight fast and were blindly assessed regarding treatment allocation at baseline and 12 weeks after study onset. Serum 25(OH)VitD levels were measured quantitatively by an enzyme immunoassay method using the reagents from DRG Instruments $\mathrm{GmbH}$ kit (DRG, Marburg, Germany). The method's analytical sensitivity is $1.28 \mathrm{ng} / \mathrm{ml}$ and the intra- and inter-assay variation is $13 \%$ for each at the level of 18 and $16 \mathrm{ng} / \mathrm{ml}$, respectively. 
Total cholesterol (TCHOL), triglycerides (TGs) and high-density lipoprotein cholesterol (HDL-C) were measured enzymatically on an Olympus AU600 Clinical Chemistry analyser (Olympus Diagnostica, Hamburg, Germany). The Friedewald formula was used to calculate serum low-density lipoprotein cholesterol (LDL-C) (when triglycerides were $<350 \mathrm{mg} / \mathrm{dl} ; 3.95 \mathrm{mmol} / \mathrm{l})$. Serum insulin was determined on an AXSYM analyser by a microparticle enzyme immunoassay (Abbott Diagnostika, Wiesbaden-Delkenheim, Germany) with a coefficient of variation of $4.2 \%$ to $9.0 \%$. The homeostasis model assessment (HOMA) index was calculated using the formula: fasting insulin ( $\mathrm{mlU} / \mathrm{l})$ $\times$ fasting glucose $(\mathrm{mg} / \mathrm{dl}) / 405$. Serum apolipoproteins $\mathrm{Al}$ (ApoAl) and B (ApoB) were measured by immunonephelometry on a Behring Nephelometer BN ProSpec (Dade-Behring, Lieberbach, Germany). The determination of $\mathrm{HbA}_{1 \mathrm{c}}$ was based on a latex agglutination inhibition assay (Randox Laboratories Ltd., Antrim, UK). $\mathrm{HbA}_{1 c}$ values are expressed as percentage of the total haemoglobin concentration. The sensitivity of the method is $0.25 \mathrm{~g} / \mathrm{dl}$ of $\mathrm{HbA}_{1 \mathrm{c}}$ and the within-run and between-run precision $<6.67 \%$ and $<4.82 \%$, respectively.

Finally, serum parathyroid hormone (PTH) was measured by IMMULITE 2500 Intact PTH, a solid-phase, two-site chemiluminescent enzymelabelled immunometric assay (Siemens Medical Solutions Diagnostics, Los Angeles, CA 90045 6900 USA).

\section{Statistical analysis}

This was a pilot study and therefore formal power calculations were not performed. The evaluation of the distribution of each variable (Gaussian or not) was done with the Kolmogorov-Smirnov test. For the variables with a Gaussian distribution data are presented as mean and standard deviation and for those with a non-Gaussian distribution they are presented as median (range, min-max). For variables that did not follow a normal distribution log-transformation was first applied. However, a normal distribution was not obtained for any variable and therefore non-parametric tests were used. The paired samples $t$-test or the Wilcoxon signed ranks test was used to assess the effect of treatment in each group. For comparisons between treatment groups we used the analysis of covariance (ANCOVA) or the Kruskal-Wallis test for non-parametric variables, adjusted for baseline values, as appropriate. Correlations between parameters were evaluated using Spearman's correlation coefficient [19]. The significance was set at $p<0.01$ due to multiple comparisons. All analyses were performed through the SPSS 18.0 statistical package for Windows (SPSS Inc., 1989-2004, Chicago, IL).

\section{Results}

The clinical and laboratory characteristics of study participants $(n=50)$ are shown in Table I.

No significant differences in baseline characteristics were noted between the 2 groups. There were also no differences in dietary intake between the groups at baseline or after the intervention (data not shown). Seventy-four percent of the participants were VitD deficient at baseline $(25(\mathrm{OH})$ VitD $<20 \mathrm{ng} / \mathrm{ml}$ ).

Three months after the intervention, a similar small weight reduction (1-2 kg) was achieved in both groups (Table II), implying poor compliance with dietary intervention in both groups (a 500 $\mathrm{kcal} /$ day reduction of energy for 3 months is expected to decrease body weight by up to $5-7 \mathrm{~kg}$ ). In the VitD group, 25(OH)VitD levels increased by $91 \%$ (from 16.0 (3.0-35.0) to $30.6(8.4-67.0) \mathrm{ng} /$ $\mathrm{ml}, p<0.001)$, while in the control group a non-significant increase by 30\% (from 10.0 (4.0-39.6) to $13.0(3.5-37.0) \mathrm{ng} / \mathrm{ml}$ ) was seen. In both groups TCHOL, TGs, HDL-C, LDL-C, ApoA1, ApoB, fasting glucose, fasting insulin, $\mathrm{HbA}_{1 c}$, HOMA index and diastolic blood pressure did not significantly change. Systolic blood pressure (SBP) decreased by 3.7\% (from $134 \pm 14$ to $129 \pm 13 \mathrm{~mm} \mathrm{Hg}, p=0.05$ ) in the VitD group, while it decreased by $1.5 \%$ in the control group (from $132 \pm 13$ to $130 \pm 16 \mathrm{~mm} \mathrm{Hg}$, $p=\mathrm{NS}$ ) (Table II). In the VitD group the increase of $25(\mathrm{OH})$ VitD levels was negatively correlated with the decrease of SBP $(r=-0.398, p=0.049)$.

\section{Discussion}

In this pilot study we found that VitD supplementation (2000 IU/day) in MetS subjects was not associated with any significant change in various CVD risk factors.

Several epidemiological studies have indicated an association between low 25(OH)VitD serum levels and MetS and/or its components [8-10, 20, 21 ], while others did not confirm these associations $[12-15,22]$. Our MetS population was $74 \%$ VitD deficient at baseline (25(OH)VitD $13 \mathrm{ng} / \mathrm{ml})$. A recently published study in diabetic patients with MetS showed a high prevalence of VitD deficiency and an inverse correlation with glycaemic control and CVD risk factors, except for HDL-C, insulin resistance and obesity. The SBP was the only factor which could be predicted from VitD concentrations [23]. Moreover, a recent study concluded that the active VitD metabolite, $1,25(\mathrm{OH})_{2}$ VitD, acting like a potent hormone that binds to VDRs and regulates transcription of several genes, is also associated with MetS and its components (i.e. high triglycerides and low HDL-C) [24]. The same study showed inverse associations between 25(OH)VitD and MetS, triglycerides and waist circumference [24]. 
Table I. Baseline characteristics of study participants

\begin{tabular}{|c|c|c|c|}
\hline Parameter & VitD suppl group & Non-suppl group & $P$-value \\
\hline$N$ & 25 & 25 & NS \\
\hline Age [years] & $52 \pm 9$ & $51 \pm 12$ & NS \\
\hline $\operatorname{Sex}(m / f)$ & $15 / 10$ & $11 / 14$ & NS \\
\hline Smoke (yes/no) & $4 / 21$ & $6 / 18$ & NS \\
\hline Weight [kg] & $89 \pm 16$ & $89 \pm 13$ & NS \\
\hline BMI $\left[\mathrm{kg} / \mathrm{m}^{2}\right]$ & $31.0 \pm 5.0$ & $33.4 \pm 6.0$ & NS \\
\hline Waist circumference $[\mathrm{cm}]$ & $107 \pm 13$ & $111 \pm 10$ & NS \\
\hline $\mathrm{SBP}[\mathrm{mm} \mathrm{Hg}]$ & $134 \pm 14$ & $132 \pm 13$ & NS \\
\hline $\mathrm{DBP}[\mathrm{mm} \mathrm{Hg}]$ & $85 \pm 6$ & $85 \pm 9$ & NS \\
\hline TCHOL $[\mathrm{mg} / \mathrm{dl}]$ & $219 \pm 36$ & $231 \pm 34$ & NS \\
\hline $\mathrm{HDL}-\mathrm{C}[\mathrm{mg} / \mathrm{dl}]$ & $48 \pm 10$ & $50 \pm 9$ & NS \\
\hline LDL-C [mg/dl] & $140 \pm 35$ & $147 \pm 26$ & NS \\
\hline TGs $[\mathrm{mg} / \mathrm{dl}]$ & $150(56-336)$ & $146(84-339)$ & NS \\
\hline Apo A1 [mg/dl] & $136 \pm 26$ & $143 \pm 13$ & NS \\
\hline Apo B [mg/dl] & $92 \pm 25$ & $107 \pm 16$ & NS \\
\hline Fasting glucose [mg/dl] & $103 \pm 15$ & $97 \pm 11$ & NS \\
\hline Fasting insulin [mg/dl] & $10.5(5.9-19.7)$ & $9.2(2-19.8)$ & NS \\
\hline HOMA index & $2.5(0.4-6.6)$ & $2.6(1.5-4.6)$ & NS \\
\hline $\mathrm{HbA}_{1 \mathrm{c}}(\%)$ & $6.2 \pm 0.8$ & $6.0 \pm 0.5$ & NS \\
\hline $25(\mathrm{OH}) \mathrm{VitD}[\mathrm{ng} / \mathrm{ml}]$ & $16(3-35)$ & $10(4-40)$ & NS \\
\hline PTH $[\mathrm{pg} / \mathrm{ml}]$ & $56 \pm 27$ & $58 \pm 20$ & NS \\
\hline MetS criteria (number of components) & $3.4 \pm 2.0$ & $3.0 \pm 2.0$ & NS \\
\hline
\end{tabular}

$B M I$ - body mass index, SBP - systolic blood pressure, DBP - diastolic blood pressure, TCHOL - total cholesterol, HDL-C - high-density lipoprotein cholesterol, LDL-C - low-density lipoprotein cholesterol, TGs - triglycerides, Apo - apolipoprotein, 25(OH)VitD - 25-hydroxy vitamin D, PTH - parathyroid hormone, MetS - metabolic syndrome, HOMA index = fasting insulin $\times$ fasting glucose/405. To convert values for triglycerides to $\mathrm{mmol} / \mathrm{l}$ multiply by 0.01129 . To convert values for cholesterol to $\mathrm{mmol} / \mathrm{l}$ multiply by 0.02586 . To convert values for glucose to mmol/l multiply by 0.05551 . To convert values for 25(OH)VitD to $\mathrm{nmol} / \mathrm{l}$ multiply by 2.5 .

However, the "VitD-CVD hypothesis" in MetS subjects has not been confirmed by reversal of CVD risk factors through VitD supplementation in a number of studies. In our study a $91 \%$ increase in $25(\mathrm{OH})$ VitD serum levels was not associated with changes in lipids, carbohydrate metabolism parameters or DBP, while a $3.7 \%$ decrease in SBP $(p=0.05)$ was observed in the intervention group. In a study of 80 MetS subjects randomized to receive 50,000 IU VitD/week for 16 weeks a significant change was found in triglycerides but not in any other metabolic or anthropometric parameters [25].

A recent large study showed that oral highdose VitD supplementation (initial dose of $200,000 \mathrm{IU}$ followed a month later by $100,000 \mathrm{IU}$ monthly or placebo) for a median of 3.3 years did not prevent CVD events. Researchers pointed out that a monthly dose may be less effective than daily or weekly doses in CVD prevention [26]. The Vitamin D and Omega-3 Trial (VITAL), a 5-year, randomized, placebo-controlled trial involving 20,000 U.S. people, is the only large study to date aiming to examine whether VitD supplementation (2000 IU/day) with or without addition of $\omega-3$ fatty acids could play a role in the primary prevention of cardiovascular disease and cancer [27].

A small non-significant drop in SBP was noted in the VitD group and the increase in $25(\mathrm{OH})$ VitD levels was marginally associated with the decrease of SBP in this group. However, no difference was noted compared with controls. Observational studies have shown that the prevalence of hypertension is lower in sunny regions, while it increases with increasing distance from the equator [28]. In a meta-analysis, levels of $25(\mathrm{OH})$ VitD 
Table II. Clinical and laboratory characteristics at baseline and 3 months after intervention

\begin{tabular}{|c|c|c|c|c|c|}
\hline Parameter & Baseline & 3 months & Change (\%) & $\begin{array}{l}P \text {-value* vs. } \\
\text { baseline }\end{array}$ & $\begin{array}{c}P \text {-value* } \\
\text { change } \\
\text { between } \\
\text { groups }\end{array}$ \\
\hline \multicolumn{6}{|l|}{ Weight [kg]: } \\
\hline VitD suppl group & $89 \pm 16$ & $88 \pm 17$ & -1.1 & NS & NS \\
\hline Non-suppl group & $89 \pm 13$ & $87 \pm 12$ & -2.2 & 0.01 & \\
\hline \multicolumn{6}{|l|}{ BMI [kg/m²]: } \\
\hline VitD suppl group & $31.0 \pm 5$ & $30 \pm 5$ & -3.2 & NS & NS \\
\hline Non-suppl group & $33.4 \pm 6$ & $32 \pm 5$ & -4.1 & 0.008 & \\
\hline \multicolumn{6}{|c|}{ Waist circumference [cm]: } \\
\hline VitD suppl group & $107 \pm 13$ & $106 \pm 13$ & -0.9 & NS & NS \\
\hline Non-suppl group & $111 \pm 10$ & $107 \pm 9$ & -3.6 & 0.002 & \\
\hline \multicolumn{6}{|l|}{$\mathrm{SBP}[\mathrm{mm} \mathrm{Hg}]:$} \\
\hline VitD suppl group & $134 \pm 14$ & $129 \pm 13$ & -3.7 & NS & NS \\
\hline Non-suppl group & $132 \pm 13$ & $130 \pm 16$ & -1.5 & NS & \\
\hline \multicolumn{6}{|l|}{$\mathrm{DBP}[\mathrm{mm} \mathrm{Hg}]$} \\
\hline VitD suppl group & $85 \pm 6$ & $83 \pm 6$ & -2.3 & NS & NS \\
\hline Non-suppl group & $85 \pm 9$ & $82 \pm 10$ & -3.5 & NS & \\
\hline \multicolumn{6}{|l|}{ TCHOL [mg/dl]: } \\
\hline VitD suppl group & $219 \pm 36$ & $224 \pm 37$ & +2.3 & NS & NS \\
\hline Non-suppl group & $231 \pm 34$ & $232 \pm 42$ & +0.4 & NS & \\
\hline \multicolumn{6}{|l|}{$\mathrm{HDL}-\mathrm{C}[\mathrm{mg} / \mathrm{dl}]:$} \\
\hline VitD suppl group & $48 \pm 10$ & $49 \pm 9$ & +2 & NS & NS \\
\hline Non-suppl group & $50 \pm 9$ & $49 \pm 10$ & -2 & NS & \\
\hline \multicolumn{6}{|l|}{ LDL-C [mg/dl]: } \\
\hline VitD suppl group & $140 \pm 35$ & $145 \pm 34$ & +3.5 & NS & NS \\
\hline Non-suppl group & $147 \pm 26$ & $152 \pm 37$ & +3.4 & NS & \\
\hline \multicolumn{6}{|l|}{ TGs [mg/dl]: } \\
\hline VitD suppl group & $150(56-336)$ & $136(46-261)$ & -9.3 & NS & NS \\
\hline Non-suppl group & $146(84-339)$ & $131(73-307)$ & -10.3 & NS & \\
\hline \multicolumn{6}{|c|}{ Fasting glucose $[\mathrm{mg} / \mathrm{dl}]$ : } \\
\hline VitD suppl group & $103 \pm 15$ & $102 \pm 23$ & -0.9 & NS & NS \\
\hline Non-suppl group & $97 \pm 11$ & $96 \pm 14$ & -1.0 & NS & \\
\hline \multicolumn{6}{|c|}{ Fasting insulin $[\mu \mathrm{U} / \mathrm{ml}]$ : } \\
\hline VitD suppl group & $10.5(5.9-19.7)$ & $9.3(3.1-27.9)$ & -11.4 & NS & NS \\
\hline Non-suppl group & $9.2(2-19.8)$ & $8.4(4.6-15.9)$ & -8.6 & NS & \\
\hline \multicolumn{6}{|l|}{ HOMA index: } \\
\hline VitD suppl group & $2.5(0.4-6.6)$ & $2.3(0.7-11.5)$ & -8 & NS & NS \\
\hline Non-suppl group & $2.6(1.5-4.6)$ & $1.8(1.0-4.5)$ & -3 & NS & \\
\hline \multicolumn{6}{|l|}{$\mathrm{HbA}_{1 \mathrm{c}}(\%):$} \\
\hline VitD suppl group & $6.2 \pm 0.8$ & $6.2 \pm 0.7$ & 0 & NS & NS \\
\hline Non-suppl group & $6.0 \pm 0.5$ & $5.6 \pm 0.5$ & -6.6 & NS & \\
\hline \multicolumn{6}{|l|}{ 25(OH)VitD [ng/ml]: } \\
\hline VitD suppl group & $16.0(3.0-35.0)$ & $30.6(8.4-67.0)$ & +91 & 0.000 & 0.007 \\
\hline Non-suppl group & $10.0(4.0-39.6)$ & $13.0(3.5-37.0)$ & +30 & NS & \\
\hline \multicolumn{6}{|l|}{ PTH [pg/ml]: } \\
\hline VitD suppl group & $56 \pm 27$ & $51 \pm 19$ & -9 & NS & NS \\
\hline Non-suppl group & $58 \pm 20$ & $48 \pm 19$ & -17 & NS & \\
\hline
\end{tabular}

${ }^{\star} P$ was considered significant if $<0.01$. BMI - body mass index, SBP - systolic blood pressure, DBP - diastolic blood pressure, TCHOL - total cholesterol, HDL-C - high-density lipoprotein cholesterol, LDL-C - low-density lipoprotein cholesterol, TGs - triglycerides, Apo - apolipoprotein, 25(OH)VitD - 25-hydroxy vitamin D, PTH - parathyroid hormone, MetS - metabolic syndrome. To convert values for triglycerides to $\mathrm{mmol} / \mathrm{l}$ multiply by 0.01129 . To convert values for cholesterol to mmol/l multiply by 0.02586 . To convert values for glucose to mmol/l multiply by 0.05551 . To convert values for $25(\mathrm{OH})$ VitD to $\mathrm{nmol} / \mathrm{l}$ multiply by 2.5 . 
were inversely associated with hypertension [29]. However, prospective studies show conflicting results, with some reporting that $25(\mathrm{OH})$ VitD levels could serve as a predictor of future hypertension, while others do not confirm this speculation $[30,31]$. The recently published Kailuan study, involving 2456 underground miners, concluded that lower $25(\mathrm{OH})$ VitD levels were not related to a greater risk of incident hypertension [32]. However, a meta-analysis by these authors, including 7 prospective studies with 53,375 participants, showed a significant association between VitD deficiency and incident hypertension [32]. Various mechanisms have been proposed for interpreting the possible anti-hypertensive effect of VitD. Previous laboratory and animal experiments associated hypovitaminosis $\mathrm{D}$ with hypertension possibly through renin-angiotensin-aldosterone system (RAAS) activation (due to insufficient suppression of renin gene expression [33]). Results from the Ludwigshafen Risk and Cardiovascular Health (LURIC) study showed that lower 25(OH)VitD and $1,25(\mathrm{OH})_{2}$ VitD levels are independently associated with up-regulated circulating RAAS [34]. Also, VitD may have a direct vascular effect, as implied by the presence of $1 \alpha$-hydroxylase activity in vascular smooth muscle and endothelial cells, the presence of VDRs in endothelial cells and its protective role against calcification in vascular smooth muscle cells in mice models [35]. However, data from interventional studies and especially from RCTs investigating the effect of VitD supplementation on blood pressure are conflicting. A meta-analysis of 4 RCTs found a reduction of SBP by $-2.44 \mathrm{~mm} \mathrm{Hg}$, but no effect on DBP [36], similarly to our findings. However, a meta-analysis by Witham et al. of 11 RCTs showed that administration of VitD and ultraviolet $A$ and $B$ radiation was associated with a non-significant SBP reduction by $-3.5 \mathrm{~mm} \mathrm{Hg}$ and a significant DBP reduction by $-3.1 \mathrm{~mm} \mathrm{Hg}$ [37]. On the other hand, a meta-analysis of 51 RCTs did not find significant effects of VitD supplementation on SBP or DBP [38]. In line with this is another meta-analysis of 46 RCTs (4541 participants) in which there was no significant effect of VitD supplementation on BP [39]. Larger RCTs targeting hypertensive patients with profound VitD deficiency are needed [40].

We found no significant change in carbohydrate metabolism indexes (fasting glucose, $\mathrm{HbA}_{1 \mathrm{c}}$, HOMA index) after VitD supplementation in patients with MetS. The association of insulin resistance with hypovitaminosis D has been extensively studied, with contrasting findings. Some observational studies showed a positive correlation between $25(\mathrm{OH})$ VitD levels and insulin sensitivity $[8,41]$, while others did not [42]. The recently published IRAS Family Study cohort showed that plasma free
$25(\mathrm{OH})$ VitD (the very small fraction of total VitD circulating unbound from VitD binding protein) appeared to have a modestly stronger relation to insulin sensitivity than the total form of serum 25(OH)VitD [43]. Most prospective studies found an inverse association between $25(\mathrm{OH})$ VitD levels and risk of insulin resistance and dysglycaemia [44-47]. Meta-analyses of prospective studies also argue for a significant association between hypovitaminosis $D$ and incident diabetes $[48,49]$. Several mechanisms have been proposed to explain the alleged association, including possible local regulation of pancreatic beta cell function [50] due to the presence of VDRs and $1 \alpha$-hydroxylase, indirect effects through calcium homeostasis [51] or even VitD-induced stimulation of osteocalcin, which may improve insulin sensitivity [52]. Overall, studies have not proved a beneficial effect of VitD supplementation on optimizing glucose metabolism parameters [53]. Some but not all studies have shown that the potential benefits of VitD supplementation could be more prominent among pre-diabetic individuals [54, 55]. Moreover, most studies in type 2 diabetes found no effect of VitD supplementation on glycaemic outcome measures [56-58]. Overall, current literature does not support the use of VitD supplements for the prevention and/or treatment of diabetes.

In our study VitD supplementation did not have any effect on serum lipids or apolipoproteins. Several cross sectional studies have demonstrated an inverse relationship between VitD deficiency and lower HDL-C as well as higher triglyceride levels $[59,60]$. Investigators speculated that $25(\mathrm{OH})$ VitD could affect lipid metabolism either directly or indirectly through alterations in parathyroid hormone and/or calcium concentrations [59]. Yet, interventional studies with VitD supplementation have led to conflicting results, with most showing that VitD supplementation might not be translated into clinically meaningful changes in lipid concentrations [61, 62]. A meta-analysis of 19 RCTs found no beneficial effect of VitD supplementation on lipid profile parameters [63].

To explain the difference between results of observational versus interventional studies it has been suggested that these associations may be confounded by shared metabolic risk factors rather than a causal relationship. Obesity alone is regarded as a causal risk factor for VitD deficiency [5]. The fat-soluble VitD could be sequestrated in the excessive body fat of obese persons, which could reduce the detectable serum levels of 25(OH)VitD [64]. In addition, obese patients have generally reduced physical activity and as a result limited sun exposure, which may lead to inadequate VitD skin synthesis. Moreover, some data suggest that an inflammatory process, which is 
usually present in these patients, might decrease 25(OH)VitD levels [65] and indirectly affect various metabolic parameters.

We noticed that parathyroid hormone (PTH) levels did not significantly change in either group (Table II). This finding is consistent with current literature which questions the utility of PTH measurements for identification of optimal VitD levels [3] and considers that the serum 25(OH)VitD and PTH relationship is inconsistent [2].

This study has certain limitations. It was a pilot study with a small number of participants. Therefore, unequivocal conclusions cannot be reached. Another limitation is that the supplementation dose (2000 IU/day) and duration (3 months) may be inadequate to treat VitD deficiency given that subjects had very low $25(\mathrm{OH})$ VitD levels at baseline. According to previous suggestions, concentrations of at least $35-60 \mathrm{ng} / \mathrm{ml}$ would be necessary [66], while in our active treatment group VitD levels only reached $30.6 \mathrm{ng} / \mathrm{ml}$.

In conclusion, we found that oral VitD supplementation (2000 IU/day) in patients with MetS did not affect various CVD risk factors, in line with most previous interventional studies.

\section{Acknowledgments}

This study was granted by the Hellenic Atherosclerosis Society (HAS).

\section{Conflict of interest}

The authors declare no conflict of interest.

\section{References}

1. Hossein-nezhad A, Spira A, Holick MF. Influence of vitamin D status and vitamin D3 supplementation on genome wide expression of white blood cells: a randomized double-blind clinical trial. PLoS One 2013; 8: e58725.

2. Institute of Medicine. Dietary reference intakes: calcium and Vitamin D. Washington DNAP, 2011.

3. Manson JE, Brannon PM, Rosen CJ, Taylor CL. Vitamin D deficiency - is there really a pandemic? N Engl J Med 2016; 375: 1817-20.

4. Holick MF. Vitamin D deficiency. N Engl J Med 2007; 357: 266-81.

5. Vimaleswaran KS, Berry DJ, Lu C, et al. Causal relationship between obesity and vitamin $D$ status: bi-directional Mendelian randomization analysis of multiple cohorts. PLoS Med 2013; 10: e1001383.

6. Holick MF. Vitamin D: the underappreciated D-lightful hormone that is important for skeletal and cellular health. Curr Opin Endocrinol Diabetes Obes 2002; 9: 87-98.

7. Makariou S, Liberopoulos EN, Elisaf M, Challa A. Novel roles of vitamin $D$ in disease: what is new in 2011? Eur J Intern Med 2011; 22: 355-62.

8. Hypponen E, Boucher BJ, Berry DJ, Power C. 25-hydroxyvitamin D, IGF-1, and metabolic syndrome at 45 years of age: a cross-sectional study in the 1958 British Birth Cohort. Diabetes 2008; 57: 298-305.
9. Strange RC, Shipman KE, Ramachandran S. Metabolic syndrome: a review of the role of vitamin $D$ in mediating susceptibility and outcome. World J Diabetes 2015; 6: 896-911.

10. Maki KC, Fulgoni VL $3^{\text {rd }}$, Keast DR, Rains TM, Park KM, Rubin MR. Vitamin D intake and status are associated with lower prevalence of metabolic syndrome in U.S. adults: National Health and Nutrition Examination Surveys 2003-2006. Metab Syndr Relat Disord 2012; 10: 363-72.

11. Ford ES, Ajani UA, McGuire LC, Liu S. Concentrations of serum vitamin $D$ and the metabolic syndrome among U.S. adults. Diabetes Care 2005; 28: 1228-30.

12. Hjelmesaeth J, Roislien J, Hofso D, Bollerslev J. Plasma 25-hydroxyvitamin D concentration and metabolic syndrome among middle-aged and elderly Chinese individuals: response to Lu et al. Diabetes Care 2010; 33: e13; author reply e14.

13. Kim S, Lim J, Kye S, Joung H. Association between vitamin D status and metabolic syndrome risk among Korean population: based on the Korean National Health and Nutrition Examination Survey IV-2, 2008. Diabetes Res Clin Pract 2012; 96: 230-6.

14. Rueda S, Fernandez-Fernandez C, Romero F, Martinez de Osaba J, Vidal J. Vitamin D, PTH, and the metabolic syndrome in severely obese subjects. Obes Surg 2008; 18: 151-4.

15. McGill AT, Stewart JM, Lithander FE, Strik CM, Poppitt SD. Relationships of low serum vitamin D3 with anthropometry and markers of the metabolic syndrome and diabetes in overweight and obesity. Nutr J 2008; 7: 4.

16. Grundy SM, Cleeman JI, Daniels SR, et al. Diagnosis and management of the metabolic syndrome: an American Heart Association/National Heart, Lung, and Blood Institute Scientific Statement. Circulation 2005; 112: 2735-52.

17. Hathcock JN, Shao A, Vieth R, Heaney R. Risk assessment for vitamin D. Am J Clin Nutr 2007; 85: 6-18.

18. Holick MF, Binkley NC, Bischoff-Ferrari HA, et al. Evaluation, treatment, and prevention of vitamin D deficiency: an Endocrine Society clinical practice guideline. J Clin Endocrinol Metab 2011; 96: 1911-30.

19. Swinscow TDV, Campbell MJ. Statistics at Square One. BMJ Books 2002; 111-5.

20. Ford ES, Zhao G, Li C, Pearson WS. Serum concentrations of vitamin $D$ and parathyroid hormone and prevalent metabolic syndrome among adults in the United States. J Diabetes 2009; 1: 296-303.

21. Reis JP, von Muhlen D, Miller ER $3^{\text {rd }}$. Relation of 25 -hydroxyvitamin $D$ and parathyroid hormone levels with metabolic syndrome among US adults. Eur J Endocrinol 2008; 159: 41-8.

22. Reis JP, von Muhlen D, Kritz-Silverstein D, Wingard DL, Barrett-Connor E. Vitamin D, parathyroid hormone levels, and the prevalence of metabolic syndrome in community-dwelling older adults. Diabetes Care 2007; 30: 1549-55.

23. Alkhatatbeh MJ, Abdul-Razzak KK, Khasawneh LQ, Saadeh NA. High prevalence of vitamin D deficiency and correlation of serum vitamin $\mathrm{D}$ with cardiovascular risk in patients with metabolic syndrome. Metab Syndr Relat Disord 2017; 15: 213-9.

24. Bea JW, Jurutka PW, Hibler EA, et al. Concentrations of the vitamin D metabolite $1,25(\mathrm{OH}) 2 \mathrm{D}$ and odds of metabolic syndrome and its components. Metabolism 2015; 64: 447-59.

25. Salekzamani S, Mehralizadeh H, Ghezel A, et al. Effect of high-dose vitamin $D$ supplementation on cardiomet- 
abolic risk factors in subjects with metabolic syndrome: a randomized controlled double-blind clinical trial. J Endocrinol Invest 2016; 39: 1303-13.

26. Scragg R, Stewart AW, Waayer D, et al. Effect of monthly high-dose vitamin D supplementation on cardiovascular disease in the vitamin $D$ assessment study: a randomized clinical trial. JAMA Cardiol 2017; 2: 608-16.

27. Manson JE. Vitamin D and the heart: why we need largescale clinical trials. Cleve Clin J Med 2010; 77: 903-10.

28. Nadir MA, Szwejkowski BR, Witham MD. Vitamin D and cardiovascular prevention. Cardiovasc Ther 2010; 28: e5-12.

29. Burgaz A, Orsini N, Larsson SC, Wolk A. Blood 25-hydroxyvitamin D concentration and hypertension: a meta-analysis. J Hypertens 2011; 29: 636-45.

30. Tamez H, Thadhani RI. Vitamin D and hypertension: an update and review. Curr Opin Nephrol Hypertens 2012; 21: 492-9.

31. Jorde R, Figenschau Y, Emaus N, Hutchinson M, Grimnes $G$. Serum 25-hydroxyvitamin D levels are strongly related to systolic blood pressure but do not predict future hypertension. Hypertension 2010; 55: 792-8.

32. Qi D, Nie XL, Wu S, Cai J. Vitamin D and hypertension: prospective study and meta-analysis. PLoS One 2017; 12: e0174298.

33. Li YC, Kong J, Wei M, Chen ZF, Liu SQ, Cao LP. 1,25-dihydroxyvitamin $D(3)$ is a negative endocrine regulator of the renin-angiotensin system. J Clin Invest 2002; 110: 229-38.

34. Tomaschitz A, Pilz S, Ritz E, et al. Independent association between 1,25-dihydroxyvitamin D, 25-hydroxyvitamin $D$ and the renin-angiotensin system: The Ludwigshafen Risk and Cardiovascular Health (LURIC) study. Clin Chim Acta 2010; 411: 1354-60.

35. Xiang W, Liao W, Yi Z, He X, Ding Y. 25-Hydroxyvitamin $D$-1-alpha-hydroxylase in apoliporotein $E$ knockout mice: the role of protecting vascular smooth muscle cell from calcification. Biomed Pharmacother 2017; 88 971-7.

36. Wu SH, Ho SC, Zhong L. Effects of vitamin D supplementation on blood pressure. South Med J 2010; 103 729-37.

37. Witham MD, Nadir MA, Struthers AD. Effect of vitamin D on blood pressure: a systematic review and meta-analysis. J Hypertens 2009; 27: 1948-54.

38. Elamin MB, Abu Elnour NO, Elamin KB, et al. Vitamin D and cardiovascular outcomes: a systematic review and meta-analysis. J Clin Endocrinol Metab 2011; 96: 1931-42.

39. Beveridge LA, Struthers AD, Khan F, et al. Effect of vitamin D supplementation on blood pressure: a systematic review and meta-analysis incorporating individual pa tient data. JAMA Intern Med 2015; 175: 745-54.

40. Tamez H, Kalim S, Thadhani RI. Does vitamin D modulate blood pressure? Curr Opin Nephrol Hypertens 2013; 22: 204-9.

41. Scragg R, Sowers M, Bell C. Serum 25-hydroxyvitamin D, diabetes, and ethnicity in the Third National Health and Nutrition Examination Survey. Diabetes Care 2004; 27: 2813-8

42. Gulseth HL, Gjelstad IM, Tierney AC, et al. Serum vitamin D concentration does not predict insulin action or secretion in European subjects with the metabolic syndrome. Diabetes Care 2010; 33: 923-5.

43. Lee C, Young K, Norris J, et al. Association of directly-measured plasma free $25(\mathrm{OH}) \mathrm{D}$ with insulin sensitivity and secretion - the IRAS Family Study. J Clin Endocrinol Metab 2017; 102: 2781-8.
44. Forouhi NG, Ye Z, Rickard AP, et al. Circulating 25-hydroxyvitamin $\mathrm{D}$ concentration and the risk of type 2 diabetes: results from the European Prospective Investigation into Cancer (EPIC)-Norfolk cohort and updated metaanalysis of prospective studies. Diabetologia 2012; 55: 2173-82.

45. Pittas AG, Nelson J, Mitri J, et al. Plasma 25-hydroxyvitamin $D$ and progression to diabetes in patients at risk for diabetes: an ancillary analysis in the Diabetes Prevention Program. Diabetes Care 2012; 35: 565-73.

46. Grimnes G, Emaus N, Joakimsen RM, et al. Baseline serum 25-hydroxyvitamin D concentrations in the Tromso Study 1994-95 and risk of developing type 2 diabetes mellitus during 11 years of follow-up. Diabet Med 2010; 27: 1107-15.

47. Anderson JL, May HT, Horne BD, et al. Relation of vitamin $D$ deficiency to cardiovascular risk factors, disease status, and incident events in a general healthcare population. Am J Cardiol 2010; 106: 963-8.

48. Afzal S, Bojesen SE, Nordestgaard BG. Low 25-hydroxyvitamin $D$ and risk of type 2 diabetes: a prospective cohort study and metaanalysis. Clin Chem 2013; 59: 381-91.

49. Song Y, Wang L, Pittas AG, et al. Blood 25-hydroxy vitamin $D$ levels and incident type 2 diabetes: a meta-analysis of prospective studies. Diabetes Care 2013; 36: 1422-8.

50. Wolden-Kirk H, Overbergh L, Christesen HT, Brusgaard K, Mathieu C. Vitamin D and diabetes: its importance for beta cell and immune function. Mol Cell Endocrinol 2011; 347: 106-20.

51. Pilz S, Kienreich K, Rutters F, et al. Role of vitamin D in the development of insulin resistance and type 2 diabetes. Curr Diab Rep 2013; 13: 261-70.

52. Wu YY, Yu T, Zhang XH, et al. 1,25(OH)2D3 inhibits the deleterious effects induced by high glucose on osteoblasts through undercarboxylated osteocalcin and insulin signaling. J Steroid Biochem Mol Biol 2012; 132: 112-9.

53. Seida JC, Mitri J, Colmers IN, et al. Effect of vitamin D3 supplementation on improving glucose homeostasis and preventing diabetes: a systematic review and metaanalysis. J Clin Endocrinol Metab 2014; 99: 3551-60.

54. Mitri J, Dawson-Hughes B, Hu FB, Pittas AG. Effects of vitamin $\mathrm{D}$ and calcium supplementation on pancreatic beta cell function, insulin sensitivity, and glycemia in adults at high risk of diabetes: the Calcium and Vitamin D for Diabetes Mellitus (CaDDM) randomized controlled trial. Am J Clin Nutr 2011; 94: 486-94.

55. Davidson MB, Duran P, Lee ML, Friedman TC. High-dose vitamin $\mathrm{D}$ supplementation in people with prediabetes and hypovitaminosis D. Diabetes Care 2013; 36: 260-6.

56. Jorde R, Figenschau Y. Supplementation with cholecalciferol does not improve glycaemic control in diabetic subjects with normal serum 25-hydroxyvitamin D levels. Eur J Nutr 2009; 48: 349-54.

57. Witham MD, Dove FJ, Dryburgh M, Sugden JA, Morris AD, Struthers AD. The effect of different doses of vita$\min D(3)$ on markers of vascular health in patients with type 2 diabetes: a randomised controlled trial. Diabetologia 2010; 53: 2112-9.

58. Soric MM, Renner ET, Smith SR. Effect of daily vitamin D supplementation on $\mathrm{HbA} 1 \mathrm{c}$ in patients with uncontrolled type 2 diabetes mellitus: a pilot study. J Diabetes 2012; 4: 104-5.

59. Jorde R, Grimnes G. Vitamin D and metabolic health with special reference to the effect of vitamin $D$ on serum lipids. Prog Lipid Res 2011; 50: 303-12. 
60. Lupton JR, Faridi KF, Martin SS, et al. Deficient serum 25-hydroxyvitamin $D$ is associated with an atherogenic lipid profile: The Very Large Database of Lipids (VLDL-3) Study. J Clin Lipidol 2016; 10: 72-81e71.

61. Ponda MP, Huang X, Odeh MA, Breslow JL, Kaufman HW. Vitamin D may not improve lipid levels: a serial clinical laboratory data study. Circulation 2012; 126: 270-7.

62. Ponda MP, Dowd K, Finkielstein D, Holt PR, Breslow JL The short-term effects of vitamin $D$ repletion on cholesterol: a randomized, placebo-controlled trial. Arterioscler Thromb Vasc Biol 2012; 32: 2510-5.

63. Challoumas D. Vitamin D supplementation and lipid profile: what does the best available evidence show? Atherosclerosis 2014; 235: 130-9.

64. Wortsman J, Matsuoka LY, Chen TC, Lu Z, Holick MF. Decreased bioavailability of vitamin D in obesity. Am J Clin Nutr 2000; 72: 690-3.

65. Reid D, Toole BJ, Knox S, et al. The relation between acute changes in the systemic inflammatory response and plasma 25-hydroxyvitamin D concentrations after elective knee arthroplasty. Am J Clin Nutr 2011; 93: 1006-11.

66. Lappe JM, Heaney RP. Why randomized controlled trials of calcium and vitamin D sometimes fail. Dermatoendocrinol 2012; 4: 95-100. 